\title{
Does Disclosure of Emotions Facilitate Recovery From Bereavement? Evidence From Two Prospective Studies
}

\author{
Margaret Stroebe, Wolfgang Stroebe, and \\ Henk Schut \\ Utrecht University
}

\author{
Emmanuelle Zech \\ University of Louvain
}

\author{
Jan van den Bout \\ Utrecht University
}

\begin{abstract}
Two longitudinal studies assessed whether disclosure of emotions facilitates recovery from bereavement. Study 1 tested prospectively over a 2-year period whether the extent to which bereaved persons talked about their loss to others and disclosed their emotions was associated with better adjustment to the loss of a marital partner. There was no evidence that disclosure facilitated adjustment. Study 2 randomly assigned recently bereaved individuals either to the Pennebaker writing task (J. W. Pennebaker \& S. K. Beall, 1986) or to no-essay control conditions. The writing task did not result in a reduction of distress or of doctors visits either immediately after the bereavement or at a 6-month follow-up. Beneficial effects were not demonstrated for bereaved persons who had suffered an unexpected loss or who at the time of the study still expressed a high need for emotional disclosure.
\end{abstract}

The notion that one must confront one's personal feelings and reactions to the death of the loved one to adjust to the loss is firmly entrenched in Western societies' beliefs about coping with grief. Despite some dissenting voices (e.g., Silver \& Wortman, 1980; M. S. Stroebe \& Stroebe, 1991; Wortman \& Silver, 1989), it is widely accepted by both lay persons and bereavement professionals that the bereaved must do their "grief work." Failure to confront the intense emotions that accompany the loss is considered maladaptive.

The concept of grief work implies a process of emotionally confronting the reality of loss, of going over events that occurred before and at the time of the death, and of focusing on memories and working toward detachment from the deceased. The concept has been central in the major theoretical formulations on grief and

Margaret Stroebe, Wolfgang Stroebe, Henk Schut, and Jan van den Bout, Department of Psychology, Research Institute for Psychology and Health, Utrecht University, Utrecht, the Netherlands; Emmanuelle Zech, Department of Psychology, University of Louvain, Louvain-la-Neuve, Belgium.

Emmanuelle Zech is funded by the Belgian Fund for Scientific Research, Belgium. Study 1 was financially supported through grants from the Nationaal Fonds voor de Geestelijke Volksgezondheid (NFGV), the Fonds Onderzoek Maatschappelijke Dienstverlening, and the Juliana Welzijn Fonds. Financial support for Study 2 was received from the NFGV. We are very grateful to the bereaved participants in the two studies, to the doctors who helped us in Study 2, and to a number of student assistants who helped with the data collection and analysis. We are also indebted to Colin Murray Parkes for his thoughtful comments on a draft of this article.

Correspondence concerning this article should be addressed to Margaret Stroebe, Department of Clinical Psychology, Utrecht University, P.O. Box 80.140, 3508 TC Utrecht, the Netherlands. E-mail: m.stroebe@ fss.uu.nl bereavement since Freud's (1917/1957) classic paper. Freud's view that grief work was necessary for the resolution of grief was shared by other major theoreticians who dominated bereavement research (e.g., Bowlby, 1980; Lindemann, 1944; Parkes, 1996). As Bowlby (1980) put it succinctly

For mourning to have a favorable outcome it appears to be necessary
for a bereaved person to endure this buffering of emotion. Only if he
can tolerate the pining, the more or less conscious searching, the
seemingly endless examination of how and why the loss occurred, and
anger at anyone who might have been responsible, not sparing even
the dead person, can he come gradually to recognize and accept that
the loss is in truth permanent and that his life must be shaped anew.
(p. 93)

Principles of counseling and therapy also assign a central role to grief work in adjustment to loss. Pathological grief is generally regarded as the failure to undergo or complete grief work. Some counseling and therapy programs for the bereaved have the goal of helping the bereaved to adapt to life without the loved one by facilitating grief work (e.g., Worden, 1991).

Although social sharing of emotions (i.e., talking to others about the emotions one experienced in reaction to the loss) may not be a necessary condition of grief work, as individuals can also confront their grief and work through it in isolation, the two processes are closely linked: People have to confront their loss in order to talk about it. Therefore the experimental work of Pennebaker and his colleagues (e.g., Pennebaker \& Beall, 1986; Pennebaker, Colder, \& Sharp, 1990; Pennebaker, Kiecolt-Glaser, \& Glaser, 1988) is relevant for the grief work hypothesis. These experimental studies found consistently that inducing participants to write about traumatic events resulted in health improvements. Respondents who were asked to disclose their emotional reactions to past traumatic experiences (e.g., Pennebaker \& Beall, 1986; Pennebaker et al., 
1988) or recent upsetting experiences (Pennebaker et al., 1990) subsequently made fewer visits to physicians than did individuals who had been instructed to write about neutral topics. This writing task has also resulted in improved immune function, as measured by enhancement in selected T-helper cell activity (Pennebaker et al., 1988) or in response to latent Epstein-Barr virus reactivation (Esterling, Antoni, Fletcher, Margulies, \& Schneiderman, 1994) and by response to hepatitis-B vaccination (Petrie, Booth, \& Pennebaker, 1995). A recent meta-analysis of studies that compared experimental conditions in which individuals wrote about traumatic topics with control conditions in which individuals wrote about neutral topics found significant long-term (3-6 months) health improvements in the experimental conditions, as indicated by reported health, psychological well-being, physiological functioning, and general functioning (Smyth, 1998).

In view of the consistency of the beneficial effects of induced emotional disclosure for other traumatic experiences, one would expect that inducing individuals to disclose their emotions about loss experiences should be particularly helpful for the bereaved. Confronting one's emotions in the course of the written or verbal disclosure task should motivate individuals to do their grief work. It is therefore puzzling that results of the few studies that induced emotional disclosure in bereaved individuals and used a randomized control group design are rather mixed (Kovac \& Range, 2000; Range, Kovac, \& Marion, 2000; Segal, Bogaards, Becker, \& Chatman, 1999).

Segal et al. (1999) assigned 30 older widowed persons (mean age, 67 years) to either a treatment or a delayed treatment group. Respondents in the treatment group were instructed to talk about the loss of their spouse and to express their deepest emotions in four 20-min vocal expression sessions during a 2-week period. Measures of distress, depression, hopelessness, and intrusionavoidance were taken before the intervention, immediately after, and 1 month after the intervention. The delayed intervention group served as a control. Experimental comparison data were only available for the first posttest, because the delayed intervention group was given the essay-writing task shortly after the posttest had been administered to the immediate intervention group. There were significant effects of time, indicating improvements of hopelessness, intrusive thoughts, obsessive-compulsive symptoms, and depression from pretest to 1-month follow-up. However, the only indication of a treatment effect was a Condition $\times$ Time of Measurement interaction on hopelessness, which appears to have been due to a slight decrease in hopelessness in the intervention group (from 4.67 at Time 1 [T1] to 3.27 at Time 2 [T2]) and a slight increase in the delayed treatment group (from 2.40 at $\mathrm{T} 1$ to 3.33 at T2). This finding is difficult to interpret because neither of the simple effects was significant.

The failure of this study to demonstrate positive health effects of induced disclosure is not conclusive, given several methodological shortcomings. The sample size was small, and the psychological health effects of the experimental manipulation could be validly assessed only immediately after the essay-writing task. There is suggestive evidence that writing emotional essays increases distress in the short term (Pennebaker et al., 1990). Finally, the choice of older adults as research participants may not have been optimal because the impact of bereavement on mental and physical health decreases with increasing age (for a review, see W. Stroebe \& Stroebe, 1987).
However, these negative findings have since been replicated in a study that used a stronger design (Range et al., 2000). Participants in this study were 64 undergraduates who within the previous 2.5 years had experienced the accidental or homicidal death of a person to whom they had been close. The precise nature of the relationship remained unspecified. Participants were asked to write on 4 consecutive days for $15 \mathrm{~min}$ about their "deepest emotions and thoughts surrounding the death" of their loved one or to write about some trivial issue (e.g., the furniture of their room). Symptoms of depression, anxiety, and grief were measured at three points: before the essay writing, after completing the last essay, and 6 weeks later. Reported health center visits were also assessed at the pretest and the follow-up. Although there were significant effects of time, indicating improvements of symptoms of depression, anxiety, and grief in the course of the study, there were no significant interactions by writing condition. Thus, even though grief symptoms abated over time, as one would expect in cases of recent bereavement, there was no evidence that writing about their "deepest feelings about the loss" was any more helpful than writing essays about trivial matters. These negative findings on the psychological measures were paralleled by the results for the reported number of doctors visits of these respondents before and after the writing task.

Finally, a study of suicide survivors showed at least partial effects of an essay-writing task (Kovac \& Range, 2000). Respondents were 40 individuals who had lost a loved one to suicide in the past 2 years. Design and procedure were similar to that of Range et al. (2000). Again, most of the measures, Impact of Event Scale (IES; Horowitz, Wilner, \& Alvarez, 1979), Grief Recovery Questionnaire (Lehman, Wortman, \& Williams, 1987), reported number of doctors visits, showed a general improvement over time with no indication of differential improvement in the group that wrote about their deepest feelings rather than a trivial topic (i.e., Condition $\times$ Time interaction). However, there was evidence for a beneficial effect of the profound- as compared with the trivialessay condition on a measure that assessed specific aspects of suicidal bereavement, namely the Grief Experience Questionnaire (Barrett \& Scott, 1989). On this measure, the bereaved individuals in the profound-essay condition improved more between posttest and follow-up than did respondents who wrote about the trivial topic.

Thus, of the three studies that assessed the impact of essay writing on coping with loss, only one study found evidence of a statistically significant beneficial effect, but this effect was limited to one of several health measures included in that study. None of the studies found any beneficial effects on doctors visits, which is the measure of choice in most of the studies of Pennebaker and colleagues (Pennebaker \& Beall, 1986; Pennebaker et al., 1988, 1990). How can we account for these inconsistencies?

One explanation could be in terms of methodology. We noted above methodological weaknesses of these studies in sample size, participant populations, or (unclear) relationship between deceased and bereaved. However, there is also a substantive reason why the impact of induced emotional disclosure may have been less strong for bereavement than for other traumatic experiences. In contrast with respondents in the typical essay-writing experiments who are asked to write about previously undisclosed traumas, bereaved individuals usually talk about their losses and disclose their emotions in natural situations (e.g., Rimé, Finkenauer, Luminet, Zech, 
\& Philippot, 1998). It would seem plausible that the extent of previous emotional disclosure moderates the health impact of the writing task.

It is therefore surprising that little is known about the role of previous disclosure as a moderator of the emotional writing task. Only one study has examined the moderating role of previous disclosure (Greenberg \& Stone, 1992). Although no difference emerged in this study in the effects of induced emotional writing on disclosed versus undisclosed traumas, the implications of this finding are unclear because no effects of induced writing were found for either type of trauma (Greenberg \& Stone, 1992). ${ }^{1}$ It is even unclear whether emotional disclosure in everyday life helps the bereaved to adjust to their loss. There is suggestive evidence from an early study of Pennebaker and O'Heeron (1984) that social sharing of emotions in everyday life has beneficial effects. Pennebaker and O'Heeron investigated the impact of confiding in others on health outcome in a survey of 19 individuals who had suffered the death of a spouse because of an automobile accident or suicide a year before. Pennebaker and O'Heeron found that the more the bereaved persons discussed their loss with others, the fewer health problems they had. However, the study was retrospective, in that individuals who had been bereaved for a year were asked to report the health complaints for the past year and in the year before their loss. On the basis of these reports, a change score was then computed, and this change score showed a positive association with disclosure. It is doubtful that individuals were able to realistically recall their health status of 2 years previously, particularly given that the 2-year period was intersected by a dramatic life event, the death of their partner.

The present article reports two longitudinal studies that assessed the relationship between disclosure and distress in bereaved samples. In Study 1, we tested prospectively whether disclosing one's grief was associated with better adjustment over a 2-year period to the loss of a marital partner. With more than 100 participants, this study not only has a substantially larger sample size than the study of Pennebaker and O'Heeron (1984), but being longitudinal, it also avoided having to rely on retrospective reports of health complaints. In Study 2, we used the Pennebaker writing task (Pennebaker \& Beall, 1986) with recently bereaved individuals. It is also longitudinal and has a number of methodological improvements: (1) larger sample size. (2) The relationship with the deceased (spouse) is standardized and meaningful, and the loss is relatively recent (within 8 months). (3) The sample includes bereaved persons whose loss was expected as well as those for whom it was sudden and unexpected, so that the study allowed us to assess the potential moderating role of the traumatic nature of the event. (4) Because previous disclosure and need for disclosure was assessed at pretest in our study, it also allowed us to control for both previous emotional disclosure and the extent to which the bereaved participants still needed to disclose their emotions in assessing the impact of the writing task. (5) Finally, objective as well as selfreport measures of health were used.

\section{Study 1}

The data on the prospective association between talking about one's loss and depressive symptomatology were collected as part of a questionnaire study, in which a sample of recently bereaved persons was assessed four times over a 2-year period following their loss (Schut, 1992).

\section{Method}

\section{Participants}

Of the 545 widowed individuals under the age of 66 who had been approached approximately 3 months after bereavement and asked to participate in this study, 379 agreed. Of these, 281 returned the first questionnaire. Assessments were carried out at 4, 11, 18, and 25 months after the deaths of their partners. Because 153 bereaved decided to stop during the course of the study, the final sample consisted of 128 participants (105 widows, 23 widowers). Because it would be unethical to exert pressure on bereaved individuals to participate, this response rate is quite typical for this type of study (M. S. Stroebe \& Stroebe, 1989).

A comparison of the 153 participants who dropped out of the study after the first point of measurement with those who completed all the questionnaires did not reveal any differences with regard to sociodemographic variables, length and quality of marriage, and expectedness of loss. However, there is some indication that those who dropped out at the third point of measurement had fewer depressive symptoms on the Depression subscale of the General Health Questionnaire (GHQ-28; Goldberg \& Hillier, 1979) during the first, $t(273)=2.56, p<.05$; and the second point, $t(182)=2.26, p<.05$, than did those who completed all four questionnaires (Schut, 1992).

\section{Procedures}

Recently bereaved individuals first received a letter describing the research project. Those for whom phone numbers were available were later phoned and asked to participate. Individuals for whom no phone numbers were available received a letter that contained a prepaid reply envelope with a response form on which they could indicate whether they wanted to participate. Those who expressed willingness then received the first questionnaire with a letter that again explained the purpose of the research project and also emphasized that respondents could stop participation at any point in time. One month later, a reminder was sent to all individuals who had not returned the questionnaire. The reminder also contained a form on which individuals could indicate the reasons why they did not return the questionnaire or decided to stop with the research. The same procedure was followed at each of the four points of measurement.

\section{Measures}

Disclosure of emotion. This was measured with a newly constructed five-item scale (e.g., "I have shown other people how I felt; I have talked to others about my loss; I gave my feelings free rein"), with four response categories (Cronbach's alpha: range $=.75-.81$; Schut, 1992).

Psychological health. This was measured with GHQ-28 (Goldberg \& Hillier, 1979). This questionnaire was designed for the detection of nonpsychotic psychiatric disturbances in general communities and is generally accepted to be a reliable and valid instrument for this purpose (Goldberg \& Williams, 1988). It is composed of four scales: Depression, Social Dysfunction, Anxiety and Sleep Problems, and Somatic Complaints. In this study, one authorized adaptation of the questionnaire was made. In the standard form of the questionnaire, individuals are asked to compare their symptom level during the previous week with their "usual level of func-

\footnotetext{
${ }^{1}$ This detail is often overlooked in reports of this study because Greenberg and Stone (1992) did find an effect of emotional writing for very severe traumas in a subanalysis of their data. However, the impact of disclosure was not assessed in this subanalysis.
} 
tioning." Because asking these recently bereaved individuals for a comparison of their present health status with their usual level of functioning might have been ambiguous, we decided to ask them to use their functioning prior to bereavement as a baseline. Cronbach's alpha for this adapted GHQ has been reported to range from .91 to .93 elsewhere (Schut, 1992; Schut, Stroebe, van den Bout, \& de Keijser, 1997).

\section{Results}

Because no difference was found between the genders in either the course or the frequency of disclosure, the data for men and women were combined. Both disclosure, $F(3,108)=40.67, p<$ .001 , and distress, $F(3,109)=4.41, p<.01$, diminished during the 2 years of the study. The cross-sectional correlations between the two variables were small and nonsignificant. We then used linear structural analyses (Jöreskog \& Sörbom, 1986) to test a model that reflected three hypotheses, namely that distress at each point in time is predicted by previous distress, that disclosure is similarly predicted by previous disclosure, and, of more interest, that disclosure affects distress and distress affects disclosure. After adding or deleting certain causal links that resulted in a significant improvement of fit of the total model, the following model (Figure 1) achieved the best fit, $\chi^{2}(8, N=128)=5.5, p=.70$, goodness of fit $(\mathrm{GOF})=.99$, root-mean-square residual $=.30$. Thus, GHQ scores at each point were best predicted by previous GHQ scores, and disclosure of emotions was best predicted by previous expression of emotion. There is little support for our main hypothesis that disclosure of emotion influenced level of distress or vice versa. The distress experienced shortly after bereavement causes more social disclosure of emotion at T2. This disclosure in turn is associated with higher levels of distress at the same point. Otherwise, none of the links between disclosure of emotion and distress is significant.

\section{Discussion}

The results of Study 1 do not support the hypothesis that sharing one's thoughts and feelings with others after the loss of a loved one reduces depressive symptomatology and facilitates adjustment. This failure to find a beneficial effect of disclosure replicates results from the Tübingen Longitudinal Study of Bereavement (M. S. Stroebe \& Stroebe, 1991). Like the present study, this earlier investigation found no evidence that talking about a loss was prospectively associated with improvements in depressive symptomatology once health status, assessed at the same time as disclosure, had been controlled for. The results of both these studies appear to be inconsistent with the finding reported by Pennebaker and O'Heeron (1984) that talking about bereavement was associated with improvements in health complaints. However, we have to remember that Pennebaker and O'Heeron found disclosure to be associated with a change score that related health complaints after bereavement to those before bereavement, with both sets of complaints assessed retrospectively. A reanalysis of the original data recently reported by Pennebaker, Zech, and Rimé (2001) found that even though disclosure was strongly positively associated with this change score, it was mildly negatively associated with the number of complaints reported for the year after bereavement, a health indicator that would be more in line with the measure used both in Study 1 and in the Tübingen study (M. S. Stroebe \& Stroebe, 1991).

In interpreting these findings, one has to keep in mind that the type of disclosures the widowed make in everyday life may differ substantially from the kind of disclosure typically made by participants in the essay-writing studies of Pennebaker and colleagues. We have always emphasized the importance of distinguishing ruminations from actual grief work in the study of the grief work hypothesis (M. S. Stroebe \& Stroebe, 1991). Grief work implies a process of confronting a loss-an active, ongoing, effortful attempt to come to terms emotionally with the loss. In contrast, ruminations reflect a passive repetition of events without any active attempts at coming to terms with the loss and all its personal implications. It seems plausible that the instructions used in the writing studies for participants to get in touch with their feelings encouraged the bereaved individuals to focus on actual grief work. In contrast, our measure of confiding may have reflected rumination as much as it did active grief work. Study 2 was conducted to assess this alternative explanation.

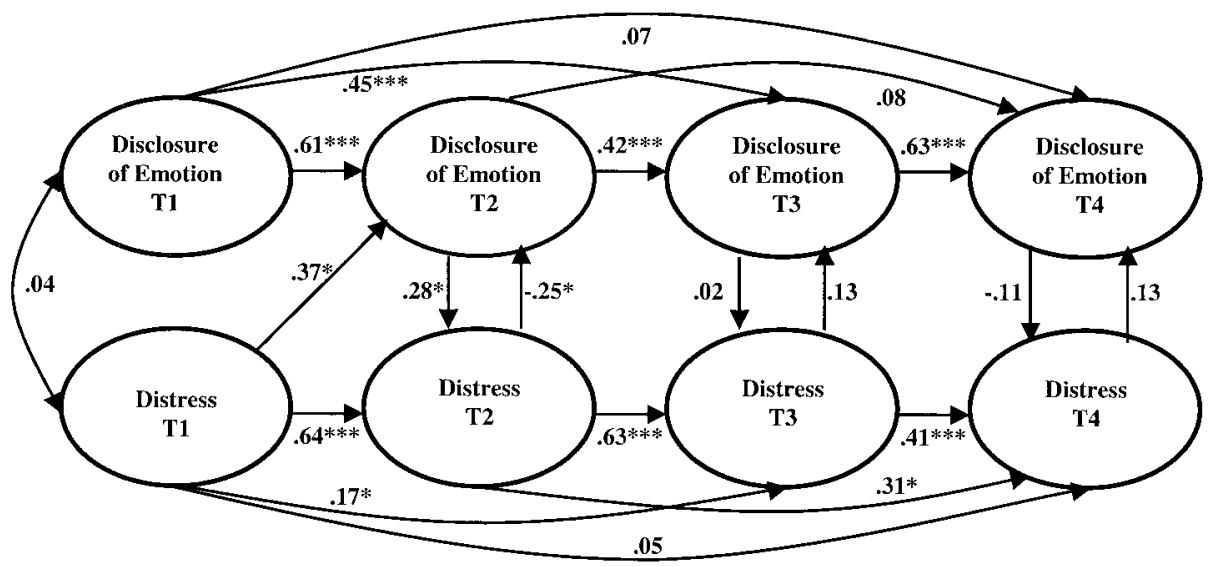

Figure 1. Regression coefficients of the causal model for the relationship between disclosure of emotions and psychological health. $* p<.05 . \quad * * * p<.001$. T1 $=$ Time $1 ; \mathrm{T} 2=$ Time 2 ; $\mathrm{T} 3=$ Time 3 ; $\mathrm{T} 4=$ Time 4. 


\section{Study 2}

Study 2 is an experimental study with bereaved individuals in which disclosure as well as the focus of disclosure were manipulated experimentally. According to the dual process model of bereavement (M. S. Stroebe \& Schut, 1999), the bereaved not only have to cope with their grief over the loss of a loved one but also to adjust to the secondary stresses due to the loss (i.e., the life changes that occur because the deceased is no longer present). We therefore instituted three writing conditions, one in which respondents had to focus on their deepest emotions, one in which the focus was on problems due to the loss, and a mixed condition that combined problems and emotions. Our two control groups consisted of bereaved persons who had not been asked to write essays.

The study design also allowed us to assess a number of situational and individual differences that might moderate the effect of disclosure on health, namely expectedness of the loss, previous disclosure, and need for disclosure. First, sudden bereavements are more traumatic experiences than losses that follow a long period of illness. As Pennebaker et al. (2001) suggested recently, the bereaved are likely to benefit more from disclosing about a sudden and traumatic loss than from disclosing about a predicted one. Second, even though Study 1 suggested that talking about their grief does not help the bereaved to adjust to their loss, we assessed frequency of past disclosure as a moderator in the present study. Third, bereaved individuals may differ in their need for disclosure. The experimentally induced emotional disclosure may only benefit those individuals who still feel a need for disclosure at the time of the experiment.

\section{Method}

\section{Participants}

Of 394 bereaved individuals under the age of 70 who were approached 4-8 months after the loss of their partners, 157 agreed to participate in a study of bereavement and could be contacted. These persons were assigned to three experimental diary writing and two control conditions. Thirty-eight of these participants failed to complete questionnaires or write diaries, leaving us with 119 participants (53 widowers, 66 widows) with complete data for the pre- and posttest measure. A comparison of the pretest scores on the GHQ and the IES of dropouts and completers did not reveal any significant differences $(t<1)$. At the 6-month follow-up, 108 respondents (48 widowers, 60 widows) could be contacted and returned questionnaires (6 did not fully complete the GHQ). We asked these 108 individuals for permission to contact their general practitioner; 104 participants agreed. Information about the number of doctors visits for the 12 months before and after the loss was finally received for 71 participants.

\section{Procedure}

Recently bereaved individuals first received a letter describing the research project and were later called to ask for their participation. Those who agreed to participate were randomly assigned to Conditions 1-4. These participants were then visited by an investigator (a trained psychology student) who explained the study and gave them the materials (pretest questionnaire and, for participants in the diary conditions, the 7-day diary). They were asked to complete the questionnaire the day after the visit and, in the diary conditions, also to start writing the day after. Thirty-four persons who had been sent a letter but could not be reached by phone contacted the investigators to ask to participate. They were assigned to the postal Condition 5.
In the three diary conditions, participants were asked to write each day for 7 consecutive days. On each day, writing instructions were repeated on the front page of the diary. The participants in the emotion group (Condition 1) were instructed as follows

Before you begin writing, remain quiet for a moment and try to be in touch with your feelings and emotions. The objective is that during 10 to 30 minutes you write down and describe as precisely as possible the feelings and emotions about the death of your husband (wife) which you experienced today, for example sadness, fear, anger or loneliness, etc.

The problem group participants (Condition 2) were instructed as follows

Before you begin writing, remain quiet for a moment and try to be in touch with the problems you have had to cope with. The objective is that during 10 to 30 minutes you write down and describe as precisely as possible the problems which you experienced today, problems caused by the changes in your daily life due to the death of your husband (wife). You can think of your work, your household or the caretaking of the children, but also of any new activity that you may have taken up since the death.

The mixed group participants (Condition 3) were to write about both their feelings and problems encountered during the day. They were instructed as follows

Before you begin writing, remain quiet for a moment and try to be in touch with your feelings and emotions and the problems you have had to cope with. The objective is that during 10 to 30 minutes you write down and describe as precisely as possible the feelings and emotions about the death of your husband (wife), which you experienced today (for example, sadness, fear, anger or loneliness), and also the problems which you had to cope with today, problems caused by the changes in your daily life due to the death of your husband (wife). You can think of your work, your household or the caretaking of the children, but also of any new activity that you may have taken up since the death.

The two control groups (Conditions 4 and 5) were not asked to keep a diary.

One week after the end of the diary or 2 weeks after having completed the first questionnaire participants were sent a second questionnaire. After 6 months, participants who had completed both pre- and posttest questionnaires as well as at least 1 day of diary writing were contacted again. Those who agreed to participate then received the 6-month follow-up questionnaire by mail and were asked to give their consent and to supply the name and address of their private doctor. At the end of the study, participants were thanked for their participation by letter and, if they wished, received a report about the study.

\section{Predictor Variables}

Expectedness of loss. Participants were asked in the pretest questionnaire about the extent to which they had expected the loss of their spouse. On the basis of the five response alternatives from 1 (completely expected) to 5 (not expected at all), the losses could be divided into those that were expected versus those that were unexpected (expected is less than or equal to 3 ; unexpected is greater than 3 ).

Frequency of disclosure. This was measured with a number of questions that assessed how often, how long, and how detailed participants were in talking about their loss to others and whether in talking about it they disclosed emotions. These items were combined into a reasonably consistent scale (Cronbach's $\alpha=.70$ ). On the basis of their answers to these questions, participants could be divided into two groups, namely high and low disclosers (split-half). 
Need for disclosure. Participants were asked about the extent to which they still felt a need to socially share and communicate about their loss. On the basis of their answers to this question, they could be divided into two groups with high or low need for disclosure (low need $\leq 3$, high need $>3$ ).

\section{Self-Report Health Measures}

$G H Q-28$. We used the same version of this questionnaire as that used in Study 1. This questionnaire was administered three times: at pretest, at the 2-week follow-up, and at the 6-month follow-up.

IES. The IES (Brom \& Kleber, 1985; Horowitz et al., 1979) taps two categories of response to a specific past trauma: intrusion (intrusively experienced ideas, images, feelings, or bad dreams) and avoidance (consciously recognized avoidance of certain ideas, feelings, or situations). The IES provides a list of 15 responses (e.g., "I had waves of strong feelings about it, I tried not to think about it"), and participants indicate with 4-point scales from 0 (not at all) to 4 (often) how frequently each response was experienced in the past 7 days. Intrusion and Avoidance scores are the sums of the relevant item subsets. Cronbach's alphas have been reported to range from .79 to .92 for Intrusion and from .82 to .91 for Avoidance (Zilberg, Weiss, \& Horowitz, 1982). This questionnaire was administered three times: at pretest and at the 2-week and 6-month follow-ups.

\section{Objective Health Measure}

Medical release forms signed by participants were mailed to their doctors, along with requests for information about medical visits made by participants during the year before bereavement and 1 year after bereavement. Physicians who did not reply were contacted again to solicit this information. Physicians were asked to provide information on dates of visits, diagnosis, and medications. Because participants were observed over a 2-year period, illness visits made at pretest (months preceding diary writing) and follow-up (months following diary writing) were averaged by month separately for each participant on the basis of actual dates of experimental participation.

\section{Analysis Strategy}

To assess the impact of essay writing on our health measures (GHQ, IES, doctors visits), we conducted four 5 (conditions) $\times 3$ (time of measurement) factorial analyses of variance (ANOVAs). To increase power, we included the postal condition (Condition 5) in this analysis, even though respondents were not randomly assigned to this condition. However, if the overall analyses revealed Condition $\times$ Time interactions, we intended to test this condition separately in the planned contrasts.

In a second step, we conducted additional $2 \times 5 \times 3$ ANOVAs to test whether the impact of the experimental manipulations was moderated by expectedness of loss, need for disclosure, and frequency of previous disclosure. Again, in the case of any interactions, planned contrasts would be used to examine differences for specific variables and specific groups.

\section{Results}

Table 1 presents the mean scores and standard deviations of the health measures taken at pretest, posttest, and follow-up for the five conditions. For doctors visits, the visits for the 4 months before the experimental intervention were used as the pretest measure. Table 1 also presents Cohen's $d$ as a measure of effect size of the change that occurred between pretest and posttest and between pretest and follow-up. According to Cohen (1977), $d=$ .20 reflects a small effect, $d=.50$ a medium effect, and $d=.80$ a large effect.

The 5 (conditions) $\times 3$ (time of measurement) ANOVA conducted on the GHQ revealed no significant main effects of conditions or time. The Condition $\times$ Time interaction did not even approach significance $(F<1)$. There was also no condition effect for Avoidance, Intrusion, and doctors visits. However, for these measures, there were significant main effects of time. Thus, symptoms of avoidance, $F(2,206)=6.00, p<.005$, and of intrusion, $F(2,206)=12.46, p<.001$, decreased significantly during the period of the study. Similarly, the number of visits to the doctor decreased over time, $F(1,65)=9.23, p<.005$. However, for all of these measures, the Condition $\times$ Time interaction did not even approach significance (all $F \mathrm{~s} \leq 1.2$ ).

To test whether the effects of the intervention would emerge for those bereaved individuals for whom the loss was sudden and unexpected, we divided respondents into two groups on the basis of a median split. We then conducted 2 (expectedness of loss) $\times 5$

Table 1

Means (and Standard Deviations) and Cohen's d of Short- and Long-Term Physical and Psychological Measures by Diary Condition

\begin{tabular}{|c|c|c|c|c|c|c|c|c|c|c|}
\hline \multirow[b]{2}{*}{ Measure } & \multicolumn{2}{|c|}{ Emotion } & \multicolumn{2}{|c|}{ Problem } & \multicolumn{2}{|c|}{ Mixed } & \multicolumn{2}{|c|}{ Control } & \multicolumn{2}{|c|}{ Postal } \\
\hline & $M(S D)$ & $d$ & $M(S D)$ & $d$ & $M(S D)$ & $d$ & $M(S D)$ & $d$ & $M(S D)$ & $d$ \\
\hline \multicolumn{11}{|c|}{ GHQ-28 $(n=102)$} \\
\hline Pretest & $9.4(5.8)$ & & $8.5(6.2)$ & & $8.3(6.0)$ & & $10.1(7.2)$ & & $10.5(8.0)$ & \\
\hline Posttest & $8.0(6.5)$ & .23 & $8.1(6.3)$ & .06 & $8.6(7.1)$ & -.05 & $9.1(7.8)$ & .13 & $8.6(8.6)$ & .23 \\
\hline Follow-up & $8.9(7.1)$ & .08 & $7.2(6.6)$ & .20 & $7.7(7.4)$ & .09 & $8.5(8.1)$ & .21 & $11.2(9.4)$ & -.08 \\
\hline \multicolumn{11}{|c|}{ Avoidance $(n=108)$} \\
\hline Pretest & $15.4(4.9)$ & & $14.5(3.0)$ & & $12.6(2.8)$ & & $15.6(5.1)$ & & $15.3(4.3)$ & \\
\hline Posttest & $13.3(4.1)$ & .46 & $14.2(3.3)$ & .09 & $12.8(2.8)$ & -.07 & $15.5(4.9)$ & .02 & $14.1(3.2)$ & .32 \\
\hline Follow-up & $12.8(3.7)$ & .60 & $13.2(3.1)$ & .43 & $12.6(3.6)$ & .00 & $15.1(4.7)$ & .08 & $13.5(3.5)$ & .46 \\
\hline \multicolumn{11}{|c|}{ Intrusion $(n=108)$} \\
\hline Pretest & $21.1(4.0)$ & & $20.3(4.8)$ & & $21.3(4.3)$ & & $22.8(3.4)$ & & $21.2(4.2)$ & \\
\hline Posttest & $19.4(4.5)$ & .40 & $19.8(4.5)$ & .11 & $20.4(5.3)$ & .19 & $20.7(4.5)$ & .53 & $20.3(3.9)$ & .22 \\
\hline Follow-up & $19.7(4.5)$ & .33 & $19.5(4.6)$ & .17 & $19.5(4.5)$ & .41 & $20.0(5.0)$ & .65 & $20.3(5.2)$ & .19 \\
\hline \multicolumn{11}{|c|}{ Doctor visits $(n=70)$} \\
\hline Pretest & $1.3(1.9)$ & & $2.1(1.6)$ & & $1.7(1.8)$ & & $3.1(2.0)$ & & $1.9(1.8)$ & \\
\hline Follow-up & $1.1(1.4)$ & .12 & $1.3(1.4)$ & .53 & $1.0(1.2)$ & .46 & $1.2(1.7)$ & 1.02 & $1.4(1.4)$ & .31 \\
\hline
\end{tabular}

Note. GHQ-28 = General Health Questionnaire; Avoidance $=$ Avoidance subscale of the Impact of Event Scale (IES); Intrusion $=$ Intrusion subscale of the IES. 
(conditions) $\times 3$ (time of measurement) factorial ANOVAs on the health measures (GHQ, IES, doctors visits). The main effects of expectedness of loss and condition did not approach significance for any of the health measures. The main effect of time of measurement emerged again as significant for Intrusion, $F(2$, $194)=13.10, p<.001$; Avoidance, $F(2,194)=5.09, p<.01$; and doctors visits, $F(1,60)=8.23, p<.01$, indicating an improvement over time on all three measures. None of the secondorder interactions or the third-order interaction approached significance for any of the health measures.

To check whether the intervention was differentially effective depending on the extent to which individuals had previously disclosed their thoughts and feeling about the loss with others, we divided respondents into two groups, namely high and low disclosers. We then conducted 2 (frequency of disclosure) $\times 5$ (conditions) $\times 3$ (time of measurement) factorial ANOVAs on the health measures (GHQ, IES, doctors visits). There was a time main effect for the Intrusion and Avoidance subscales of the IES and on doctors visits. Over time, Intrusion, $F(2,194)=9.56, p<.01$; Avoidance, $F(2,194)=5.77, p<.005$; and number of doctors visits, $F(1,60)=7.53, p<.05$, decreased, but this decrease was independent of the experimental manipulation $(F<1)$. There was also a frequency of disclosure main effect on Intrusion, $F(1$, $93)=5.18, p<.05$, and on doctors visits, $F(1,60)=8.01, p<$ .05 . Low disclosers showed lower levels of intrusion $(M=19.53)$ than high disclosers $(M=21.44)$ and had also fewer visits to their doctor $(M=1.11$ vs. 1.94$)$.

Finally, we assessed whether the intervention was effective for those individuals who still had a need to socially share and to communicate about their loss. Respondents were divided into groups with high or low need for disclosure on the basis of a median split. We then conducted 2 (need for disclosure) $\times 5$ (conditions) $\times 3$ (time of measurement) factorial ANOVAs on the four health measures. There were the usual main effects of time on Intrusion, $F(2,194)=11.39, p<.005$, and on doctors visits, $F(1$, $60)=10.27, p<.01$, indicating improvement over time on both measures. For the GHQ, there was a significant main effect of need for disclosure, $F(1,91)=16.97, p<.001$. None of the other main effects or second-order interactions approached significance. However, there was a Need for Disclosure $\times$ Conditions $\times$ Time interaction, $F(8,182)=3.06, p<.005$. This interaction appears to be due to the fact that in the control group individuals with a low need to share improved over time, whereas individuals with a high need to share did not (Figure 2). The latter group even showed a slight increase over time in their GHQ scores. This type of differential effect does not seem to occur for the three essay-writing conditions. However, as even at Time 3 there was no significant Condition $\times$ Need for Disclosure interaction and as the difference between the two control groups and the experimental groups at Time 3 was not significant, $t(99)=-1.18, n s$, this pattern is difficult to interpret.

\section{Discussion}

The findings of this study provide little evidence for a beneficial effect of essay writing for bereaved individuals. There was no indication of an interaction between conditions and time for any of the health measures. Thus, confronting their emotions in the course of the essay-writing task, or writing about the problems in their
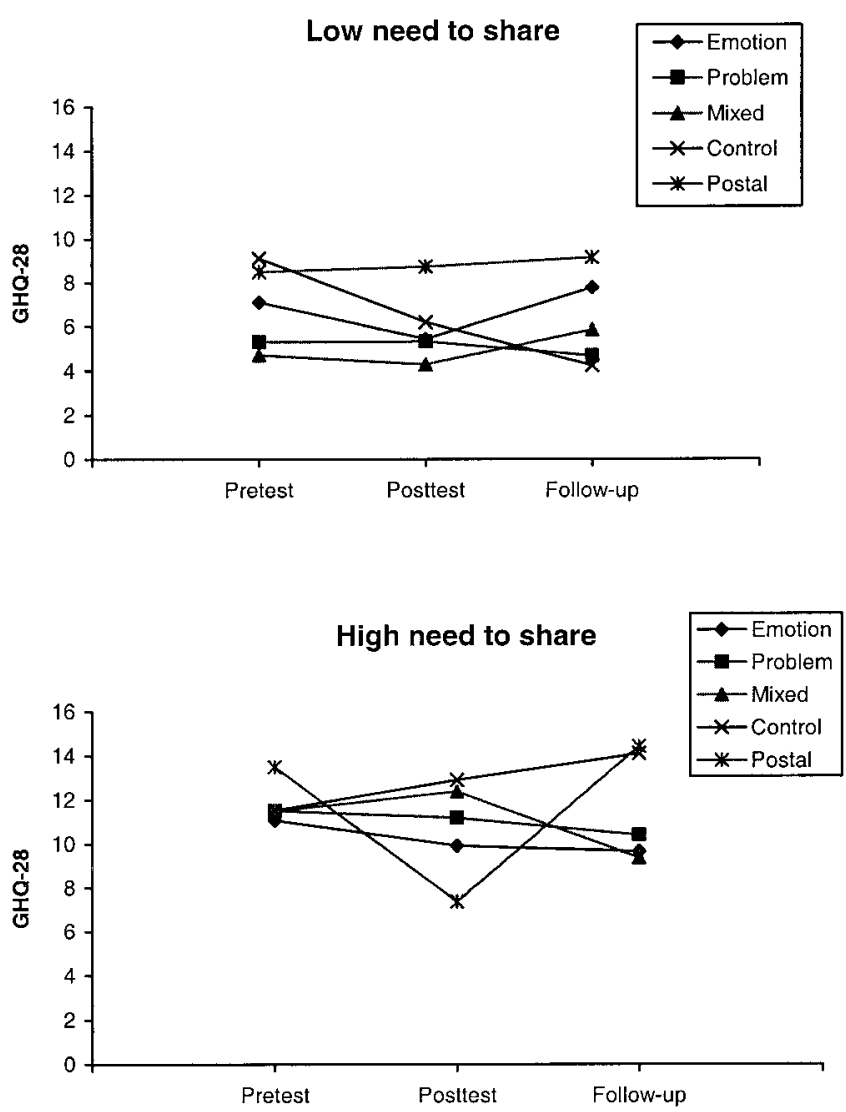

Figure 2. Mean General Health Questionnaire (GHQ-28) scores at pretest, posttest, and follow-up by need to share.

daily life as a result of their loss, did not appear to help the bereaved adjust to their loss. None of the experimental groups was significantly better off at follow-up than either of the two control groups (see Table 1).

In view of the weak overall effects of writing-induced disclosure in past research, we had assumed that the impact of disclosure might only emerge under certain conditions. However, although we assessed most of the likely moderator variables in this study, there was no evidence of a differential effect of the experimental conditions. Thus, Pennebaker et al. (2001) have recently suggested that the beneficial effects of writing-induced emotional disclosure might only emerge for bereavements that are relatively traumatic, such as sudden and unexpected losses. However, when we divided the bereaved participants into those who had expected the loss and those who had not, there was no indication that writing-induced disclosure had more beneficial effects for bereaved individuals who suffered an unexpected loss than it had for those whose partner died expectedly after a long illness.

Another plausible moderator of the impact of writing-induced disclosure appeared to us to be the frequency with which the bereaved individuals had already engaged in social sharing before and had already disclosed their deepest emotions about the loss to others. It would seem plausible that the beneficial effects of writing-induced disclosure are weakened to the extent that individuals have already engaged in disclosure as part of their every- 
day interactions with others. However, there was no indication that the frequency with which the bereaved participants in our study had previously talked about their loss to others moderated the impact of writing-induced disclosure. The fact that low disclosers suffered less from intrusive thoughts and also had fewer visits to the doctor than high disclosers actually suggests that rather than facilitating adjustment, the extent to which the bereaved disclose their emotions may be a symptom of poor recovery.

Finally, we assessed the extent to which individuals still felt a need to disclose their emotions as a potential moderator of the effectiveness of writing-induced disclosure. There is a great deal of empirical evidence that a high need to socially share an event is an indication that recovery has not yet taken place (e.g., Rimé et al., 1998; Zech, 1999, 2000). Therefore, it seemed plausible that those bereaved individuals who still have a strong need to share their loss experience 4 to 8 months after the death of their partner are the ones who will benefit most from the writing intervention. Although the interaction between need for disclosure, experimental conditions, and time is suggestive, the actual pattern of this interaction evident in the results does not really provide support for this hypothesis. At the end of the follow-up period, the bereaved participants in the essay-writing condition were not significantly better adjusted to their loss than were participants in the two control conditions.

\section{General Discussion}

Consistent with previous studies on the effects of the Pennebaker essay-writing task on adjustment to loss, the research presented in this article indicates that distress, intrusion and avoidance related to the loss, and number of illness visits to doctors decreased over time in all conditions. This appears to reflect the course of usual adjustment to bereavement over time. However, the present studies did not provide support for the notion that emotional disclosure about one's loss facilitates adjustment. Of the three previously published studies that used the Pennebaker essaywriting task to experimentally induce emotional disclosure (and used a randomized control group), only one found an interpretable interaction between condition and time and only on one of the five measures of health outcome used (Kovac \& Range, 2000). The bereaved in that study had lost a person to whom they had been close through that person's suicide. Suicide death might be expected to result in greater problems of adjustment than would deaths from other causes. However, there is little empirical evidence to support this contention. In fact, the few studies that compared the psychological consequences of bereavement due to suicide with that of other forms of losses have typically failed to find any marked differences in bereavement outcome (Cleiren, 1991; Farberow, Gallagher-Thompson, Gilewski, \& Thompson, 1992; Shepherd \& Barraclough, 1974; Sherkat \& Reed, 1992). Nevertheless, as voluntary deaths, suicide deaths are characterized by features that set them apart from normal losses. It is therefore noteworthy that bereaved individuals writing about their deepest feelings about this loss rather than a trivial topic decreased only suicide-specific grief cognitions but did not reduce general grief, intrusion or avoidance of the event, or health center visits. This last finding raises the possibility that emotional disclosure may have beneficial effects for individuals who lost a person to suicide, but beneficial effects are limited to cognitions that are especially relevant for suicide survivors (e.g., the idea of being rejected by the loved one).

With regard to nonsuicide deaths, there is no evidence that emotional disclosure facilitates adjustment either from the two published studies (Range et al., 2000; Segal et al., 1999) or from our own studies. Our first study failed to find any prospective association between talking about one's loss and depressive symptomatology in a sizable sample of bereaved spouses. According to the best-fitting model, the level of distress at each point in time was best predicted by the previous level of distress and the expression of emotions was best predicted by previous expression of emotion. There was no support for the assumption that disclosure of emotions resulted in a reduction of distress. Similarly, our second study did not find any evidence that writing-induced disclosure facilitated adjustment to the death of a spouse, regardless of whether the death was expected or sudden and unexpected. Beneficial effects could not even be demonstrated for bereaved who had not previously talked a great deal about their loss or who at the time of the essay writing had still felt a great need for disclosure. It is noteworthy, however, that significant improvements of symptoms of distress, avoidance, intrusion, and doctors visits were found over time, suggesting that, in case of nonsuicide deaths, time was a healer.

Given that the death of a spouse is considered the most stressful of all in lists of stressful life events (e.g., Holmes \& Rahe, 1967), the failure to find a beneficial effect of disclosure of emotions would appear surprising. However, one major difference between bereavement and the traumas for which the impact of the Pennebaker writing task has typically been assessed in the past is that, in the case of bereavement, the writing task is superimposed on the normal process of change and recovery expected for the recently bereaved. Thus, the impact of the writing task would have to add to the effects of the normal process of adjustment to the death of a loved one. In contrast, with the often-undisclosed traumas that have been used in most of the previous research with the Pennebaker writing task, no changes are expected to occur in the control conditions. In other words, without the intervention, the trauma is expected to remain unresolved.

It is interesting to note that our findings are consistent with the pattern that emerged in a recent review of the efficacy of different types of general preventive interventions for bereaved individuals (Schut, Stroebe, van den Bout, \& Terheggen, 2001). Bereavement interventions proved to be only effective for individuals who suffered from complicated grief and felt themselves in need of professional help. Complicated grief is marked by a deviation from the norm in the time course or intensity of specific or general symptoms of grief. For some reasons, these bereaved appear to be unable to resolve their grief and to adjust to their loss. Schut et al. (2001) found no evidence that counseling or therapy helped normally bereaved individuals who did not themselves seek professional help. As there was no indication that any of the participants in our study suffered from complicated grief, and as our participants were not seeking professional help, they represented a group who would probably not have profited from therapy or counseling. Given that induced emotional disclosure constitutes a minimal form of therapy, the lack of effect with this group may therefore not be surprising.

This finding is also consistent with the pattern that emerged in our study of the impact of social support in bereavement (W. 
Stroebe, Stroebe, Abakoumkin, \& Schut, 1996). In a longitudinal study of the influence of social support on psychological wellbeing of bereaved and nonbereaved men and women, we found no evidence of a differential effect of social support for the bereaved. Although individuals who perceived their level of social support as high were less likely to show depressive symptomatology than were individuals who thought they had little support, this beneficial effect was of the same magnitude for bereaved and nonbereaved alike. Taken together, these findings suggest that in cases of uncomplicated bereavement the bereaved have to cope with their loss in their own time and their own way. Although social sharing and emotional disclosure can be regarded as helpful, they do not seem to accelerate the grieving process.

\section{References}

Barrett, T. W., \& Scott, T. B. (1989). Development of the Grief Experience Questionnaire. Suicide and Life-Threatening Behavior, 19, 201-215.

Bowlby, J. (1980). Attachment and loss: Vol. 3. Loss: Sadness and depression. London: Hogarth.

Brom, D., \& Kleber, R. (1985). De Schok Verwerkingslijst [The Impact of Event Scale]. Nederlands Tijdschrift voor de Psychologie, 40, 164-168.

Cleiren, M. P. H. D. (1991). Adaptation after bereavement. Leiden, the Netherlands: DSWO Press.

Cohen, J. (1977). Statistical power analysis for the behavioral sciences (Rev. ed.). New York: Academic Press.

Esterling, B., Antoni, M. H., Fletcher, M., Margulies, S., \& Schneiderman, N. (1994). Emotional disclosure through writing or speaking modulates Epstein-Barr virus antibody titers. Journal of Consulting and Clinical Psychology, 62, 130-140.

Farberow, N. L., Gallagher-Thompson, D., Gilewski, M., \& Thompson, L. (1992). Changes in grief and mental health of bereaved spouses of older suicides. Journal of Gerontology, 47, 357-366.

Freud, S. (1957). Mourning and melancholia. In J. Strachey (Ed. \& Trans.), Standard edition of the complete psychological works of Sigmund Freud. London: Hogarth Press. (Original work published 1917)

Goldberg, D. P., \& Hillier, V. F. (1979). A scaled version of the General Health Questionnaire. Psychological Medicine, 9, 139-145.

Goldberg, D. P., \& Williams, P. (1988). A user's guide to the General Health Questionnaire. Windsor, England: NFER Publishing Group.

Greenberg, M. A., \& Stone, A. A. (1992). Emotional disclosure about traumas and its relation to health: Effects of previous disclosure and trauma severity. Journal of Personality and Social Psychology, 63, $75-84$.

Holmes, T., \& Rahe, R. (1967). The Social Readjustment Rating Scale. Journal of Psychosomatic Research, 11, 213-218.

Horowitz, M., Wilner, N., \& Alvarez, W. (1979). Impact of Event Scale: A measure of subjective stress. Psychosomatic Medicine, 41, 209-218.

Jöreskog, K. G., \& Sörbom, D. (1986). LISREL VI user's guide (2nd ed.). Mooresville, Indiana: Scientific Software.

Kovac, S. H., \& Range, L. M. (2000). Writing projects: Lessening undergraduates' unique suicidal bereavement. Suicide and Life-Threatening Behavior, 30, 50-60.

Lehman, D. R., Wortman, C. B., \& Williams, A. F. (1987). Long-term effects of losing a spouse or child in a motor vehicle crash. Journal of Personality and Social Psychology, 52, 218-231.

Lindemann, E. (1944). Symptomatology and management of acute grief. American Journal of Psychiatry, 101, 141-148.

Parkes, C. M. (1996). Bereavement: Studies of grief in adult life. London: Routledge.

Pennebaker, J. W., \& Beall, S. K. (1986). Confronting a traumatic event: Toward an understanding of inhibition and disease. Journal of Abnormal Psychology, 95, 274-281.
Pennebaker, J. W., Colder, M., \& Sharp, L. K. (1990). Accelerating the coping process. Journal of Personality and Social Psychology, 58, $528-537$.

Pennebaker, J. W., Kiecolt-Glaser, J., \& Glaser, R. (1988). Disclosure of traumas and immune function: Health implications for psychotherapy. Journal of Consulting and Clinical Psychology, 56, 239-245.

Pennebaker, J. W., \& O'Heeron, R. C. (1984). Confiding in others and illness rate among spouses of suicide and accidental death victims. Journal of Abnormal Psychology, 93, 473-476.

Pennebaker, J. W., Zech, E., \& Rimé, B. (2001). Disclosing and sharing emotion: Psychological, social and health consequences. In M. S. Stroebe, R. O. Hansson, W. Stroebe, \& H. Schut (Eds.), Handbook of bereavement research: Consequences, coping, and care. Washington, DC: American Psychological Association.

Petrie, K., Booth, R., \& Pennebaker, J. W. (1995). Disclosure of traumas and immune response to a hepatitis B vaccination program. Journal of Consulting and Clinical Psychology, 63, 787-792.

Range, L. M., Kovac, S. H., \& Marion, M. S. (2000). Does writing about bereavement lessen grief following sudden, unintentional death? Death Studies, 24, 115-134.

Rimé, B., Finkenauer, C., Luminet, O., Zech, E., \& Philippot, P. (1998). Social sharing of emotions: New evidence and new questions. In W. Stroebe \& M. Hewstone (Eds.), European review of social psychology (Vol. 8, pp. 145-190). Chichester, England: Wiley.

Schut, H. (1992). Omgaan met de dood van de partner: Effecten op gezondheid en effecten van rouwbegeleiding. [Coping with conjugal bereavement: Effects on psychological functioning and effects of grief counseling]. Amsterdam: Thesis Publishers.

Schut, H., Stroebe, M., van den Bout, J., \& de Keijser, J. (1997). Gender differences in the efficacy of grief counseling. British Journal of Clinical Psychology, 36, 63-72.

Schut, H., Stroebe, M. S., van den Bout, J., \& Terheggen, M. (2001). The efficacy of bereavement intervention: Who benefits? In M. S. Stroebe, R. O. Hansson, W. Stroebe, \& H. Schut (Eds.), Handbook of bereavement research: Consequences, coping, and care. Washington, DC: American Psychological Association.

Segal, D. L., Bogaards, J. A., Becker, L. A., \& Chatman, C. (1999). Effects of emotional expression on adjustment to spousal loss among older adults. Journal of Mental Health and Aging, 5, 297-310.

Shepherd, D., \& Barraclough, B. M. (1974). The aftermath of suicide. British Medical Journal, 2, 600-603.

Sherkat, D. W., \& Reed, M. D. (1992). The effects of religion and social support on self-esteem and depression among the suddenly bereaved. Social Indicators Research, 26, 259-275.

Silver, R. C., \& Wortman, C. (1980). Coping with undesirable life events. In J. Garber \& M. E. Seligman (Eds.), Human helplessness (pp. 279375). New York: Academic Press.

Smyth, J. M. (1998). Written emotional expression: Effect sizes, outcome types, and moderating variables. Psychological Bulletin, 66, 174-184.

Stroebe, M. S., \& Schut, H. W. (1999). The dual process model of coping with bereavement: Rationale and description. Death Studies, 23, 197224.

Stroebe, M. S., \& Stroebe, W. (1989). Who participates in bereavement research? An empirical study of the impact of health on attrition. Omega, 20, 1-29.

Stroebe, M. S., \& Stroebe, W. (1991). Does grief work, work? Journal of Consulting and Clinical Psychology, 59, 479-482.

Stroebe, W., \& Stroebe, M. S. (1987). Bereavement and health: The psychological and physical consequences of partner loss. New York: Cambridge University Press.

Stroebe, W., Stroebe, M. S., Abakoumkin, G., \& Schut, H. (1996). The role of loneliness and social support in adjustment to loss: A test of attachment versus stress theory. Journal of Personality and Social Psychology, 70, 1241-1249. 
Worden, J. W. (1991). Grief counseling and grief therapy: A handbook for the mental health practitioner. New York: Springer.

Wortman, C., \& Silver, R. C. (1989). The myths of coping with loss. Journal of Consulting and Clinical Psychology, 57, 349-357.

Zech, E. (1999). Is it really helpful to verbalize one's emotions? Gedrag \& a Gezondheid, 27, 42-47.

Zech, E. (2000). The effects of the communication of emotional experiences. Unpublished doctoral dissertation, University of Louvain, Department of Psychology, Louvain, Belgium.
Zilberg, N. J., Weiss, D. S., \& Horowitz, M. J. (1982). Impact of Event Scale: A cross-validation study and some empirical evidence supporting a conceptual model of stress response syndromes. Journal of Consulting and Clinical Psychology, 50, 407-414.

Received November 2, 2000 Revision received February 26, 2001

Accepted March 17, 2001

\section{Low Publication Prices for APA Members and Affiliates}

Keeping you up-to-date. All APA Fellows, Members, Associates, and Student Affiliates receive-as part of their annual dues-subscriptions to the American Psychologist and APA Monitor. High School Teacher and International Affiliates receive subscriptions to the APA Monitor, and they may subscribe to the American Psychologist at a significantly reduced rate. In addition, all Members and Student Affiliates are eligible for savings of up to $60 \%$ (plus a journal credit) on all other APA journals, as well as significant discounts on subscriptions from cooperating societies and publishers (e.g., the American Association for Counseling and Development, Academic Press, and Human Sciences Press).

Essential resources. APA members and affiliates receive special rates for purchases of APA books, including the Publication Manual of the American Psychological Association, and on dozens of new topical books each year.

Other benefits of membership. Membership in APA also provides eligibility for competitive insurance plans, continuing education programs, reduced APA convention fees, and specialty divisions.

More information. Write to American Psychological Association, Membership Services, 750 First Street, NE, Washington, DC 20002-4242. 